\title{
DEVELOPMENT OF A HAZARD MAPPING METHOD FOR DEBRIS FLOW IN DISASTER-PRONE AREAS
}

\author{
TingYeh $\mathrm{WU}^{1}$ and Kaoru TAKARA ${ }^{2}$ \\ ${ }^{1}$ Studnet Member, Graduate student, Dept. of Urban and Environment Eng., Kyoto University \\ (Kyoto 615-8540, Japan) \\ ${ }^{2}$ Fellow of JSCE, Dr. Eng., Professor, DPRI, Kyoto University (Gokasho, Uji 611-0011, Japan)
}

\begin{abstract}
Morphological and hydrological conditions are main factors to influence the probability and magnitude of sediment disasters. This study tried to develop a method for hazard mapping of sediment disasters from these two aspects. Aerial photographs and historical debris flow susceptibility analysis were used to distinguish the potential debris flow torrents, digital terrain model was used to make the topographic data, and hydrologic frequency analysis was used to evaluate the probable discharges extreme value from two survey stations in a study watershed in Taiwan. Finally, the results made in the first part were input in the Flo-2D software model to simulate the deposited area for each torrent. To create a hazard map, the results from simulation were divided into several levels in terms of danger based on landslide intensity.
\end{abstract}

key words: debris flow, Flo-2D, hazard mapping

\section{INTRODUCTION}

Sediment movement includes rock fall, landslide and debris flow, always results in serious damage on properties and human lives, so that a sediment hazard mapping is necessary. In order to distinguish the potential dangerous level of sediment disaster-prone areas and identify the adequate disaster reduction activities, hazard mapping is one the main parts of disaster analysis.

Although many natural disasters, such as cyclone, flood and typhoon, could be forecasted with magnitude and intensity from historic records and continuous monitoring data before these disasters happened. However, because of many interaction factors, predictions of sediment disasters have been uncertain and is difficult to evaluate in the real happening time. Therefore, in the previous study by Okimura $^{1)}$, researchers used several methods to estimate approximate probability or danger level for sediment disasters, which could be divided into the statistic method, numerical topographic model, score method, distribution of surface soil, and etc.

The score method evaluates several ranks of factors and the sum of points could be compared according to total point to determine the danger level. The statistic method is considered the most appropriate approach for hazard mapping and presents how disaster would happen by probability. ${ }^{2)}$ On the other hand, some researchers are aiming on analyses of physical factors with historical landslide events to show how landslide happen by numerical simulation. However, most of the previous studies using these methods could only calculated the probability of landslide happened, and very few studies were reported by probability and numerical simulation at the same time.

On the other hand, researchers tried many methods to quality and quantify the hazard of Chenyoulanxi River because of its high frequency debris flow disasters in recent years. However, due to the lack of the precised hydrological analysis, the credibility is not good. As the reasons had been mentioned, we try to find a reasonable and precise method to develop a hazard mapping for landslide disasters. The two aspects, morphological and hydrological factors, were considered $^{3}$. For hydrological factor, we consulted the Japanese papers to calculate the discharge for each torrent, and for morphological factor, aerial photograph was used to identify the topographic characteristics of debris flow. Finally, the hazard map was drawn by the simulation result from Flo-2D software model.

\section{STUDY AREA AND SIMULATION TOOL}




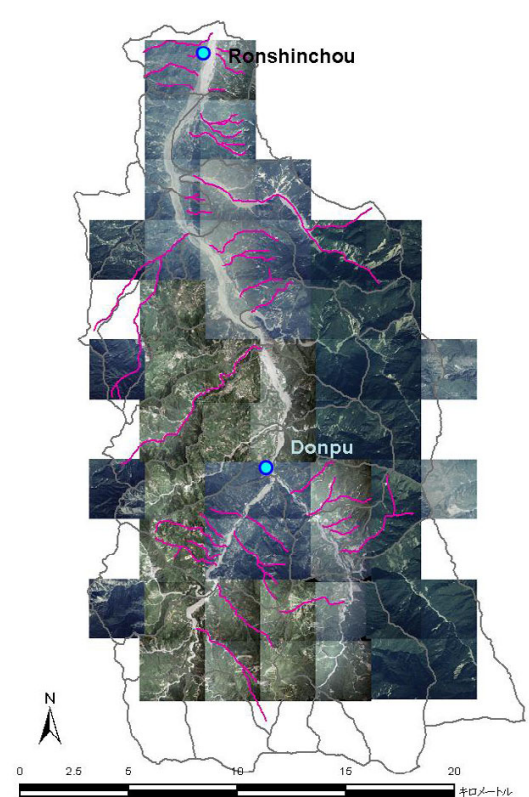

Fig.1 Chenyouranxi watershed

\section{(1) Study area}

The Chenyoulanxi River valley, located in the middle of Taiwan, is the study area, which is one of the main tributaries of the Zhuoshuixi River. Due to pass through a fault and developed alluvial fans, the Chenyoulanxi valley is a fault-line valley. The weak geologic conditions between right and left banks and the influence of fault, which cause steeping hill slope and landslide, and the serious soil erosion in this watershed ${ }^{4), 5)}$ are the main reasons to make this watershed become one of the highest sediment concentrated rivers in the world.

From 1996 to 2005, according to the investigated reports published by the Soil and Water Conservation Bureau in Taiwan (SWCB), 7 catastrophic typhoons passed and brought heavy rainfall, each of them caused serious debris flows and landslide events. The maximum rainfall intensity had reached to $237 \mathrm{~mm}$ per hour, and the maximum year of total precipitation in this watershed is $2909 \mathrm{~mm}$. Due to the geologic and hydrologic conditions, the Chenyouranxi watershed is one of the most disaster-prone areas in Taiwan.

Because of the effect brought from big earthquake in 1999, there had been 34 torrents defined as potential debris flow torrents ${ }^{6)}$, where some monitoring facilities were set up to record. However, it could be found that from historic records, more and more sediment disasters happened not only on these defined torrents, but on the other undefined places, such as hillslopes, floodplains, and fans. In particular, there are lots of alluvial fans distributed in this watershed, and these areas are also places residents and properties crowd in.

\section{(2) Flo-2D simulation model}

We used Flo-2D software model to simulate each torrents for anglicizing the deposit area and plots the hazard map. The Flo-2D software is a two dimensional flood routing model made by Jimmy S. O'Brien ${ }^{7}$. Continuity equation and dynamic wave momentum equation are the basic concepts of this model, as Eqs. (1), (2) and (3)

$$
\begin{gathered}
\frac{\partial h}{\partial t}+\frac{\partial h V_{x}}{\partial x}+\frac{\partial h V_{y}}{\partial y}=i \\
S_{f x}=S_{o x}-\frac{\partial h}{\partial x}-\frac{V_{x}}{g} \frac{\partial V_{x}}{\partial x}-\frac{V_{y}}{g} \frac{\partial V_{x}}{\partial y}-\frac{1}{g} \frac{\partial V_{x}}{\partial t} \\
S_{f y}=S_{o y}-\frac{\partial h}{\partial y}-\frac{V_{y}}{g} \frac{\partial V_{y}}{\partial y}-\frac{V_{x}}{g} \frac{\partial V_{y}}{\partial x}-\frac{1}{g} \frac{\partial V_{y}}{\partial t}
\end{gathered}
$$

where $S_{f x}$ is friction slope component, which is based on Manning's equation. The other terms include the bed slope $S_{o x}$, pressure gradient, convective acceleration and local acceleration. This program assumes a Bingham fluid and uses the equations solve the height $(h)$ and average velocity in $\mathrm{x}$ and $\mathrm{y}$ axes $\left(V_{x}, V_{y}\right)^{8}$.

This software is used in situation of urban flooding, floodplain flooding management and irregular channel simulations by mudflow, overland flow or debris flow $^{9)}$. To operate this software, a digital terrain map with $20 \mathrm{~m}$ element size is needed to decide the simulated range, and topographic information is set up in the main scene, such as Manning's value, Froude number, bulking concentration, etc. On the other hand, the rainfall and discharge data could be input as hydrologic conditions.

\section{ANALYSES METHOD}

In this study, the analysis procedure is mainly divided into two parts; the first one is to check input data and simulating objects, and the second one is to plot the hazard map. It involves four main steps:

Step 1: To recognize aerial photographs to check the torrents to be analyzed,

Step 2: To calculate discharges of torrents from discharge and rainfall data,

Step 3: To simulate torrents with the result of Step 1 and Step 2,

Step 4: To make divisions from simulated results and show the hazard map.

These steps are described as follows.

Step1: The aerial photographs taken in 2002 and historical debris flow susceptibility analysis made by the SWCB, Taiwan, were compared to check the location, watershed area, length, the probable points that debris flow may happen. However, there were still many rills, landslide on hillslopes, and torrents could be distinguished from aerial photographs which are exception of potential debris flow defined 
Table 1 Debris flow velocity scale

\begin{tabular}{|c|c|c|c|}
\hline Velocity class & Description & $\begin{array}{l}\text { Velocity } \\
(\mathrm{m} / \mathrm{s})\end{array}$ & $\begin{array}{l}\text { Typical human } \\
\text { response }\end{array}$ \\
\hline 6 & Extremely rapid & \multirow{2}{*}{10.00} & Nil \\
\hline 5 & rapid & & Nil \\
\hline 4 & Moderate & 6.67 & Evacuation \\
\hline 3 & Slow & 1.56 & Evacuation \\
\hline 2 & Very slow & 1.00 & Maintenance \\
\hline & & 0.61 & \\
\hline 1 & Extreme slow & 0 & Maintenance \\
\hline
\end{tabular}

Table 3 results of SLSC

\begin{tabular}{l|c|c}
\hline \multirow{2}{*}{ Distributions } & \multicolumn{2}{c}{ SLSC(99\%) } \\
\cline { 2 - 3 } & Ronshinchou & Donpu \\
\hline Exp & 0.050 & 0.064 \\
\hline Gumbel & 0.061 & 0.081 \\
\hline SqrtEto & 0.075 & 0.042 \\
\hline GEV & 0.060 & 0.042 \\
\hline Iwai & 0.054 & 0.033 \\
\hline LN3Q & 0.053 & 0.035 \\
\hline Lexp & 0.116 & 0.110 \\
\hline Gp & 0.040 & 0.020 \\
\hline GpExp & 0.200 & 0.155 \\
\hline
\end{tabular}

by the SWCB,. Therefore, we checked these places and then made a hypothesis that in these places, debris flow may happen under the condition of extreme discharge value.

Step 2: Rainfall and discharge data were used to have a hydrologic frequency analysis. We collected both daily rainfall and discharge data from two rainfall stations and survey stations. Ronshinchou station is one of which located in the north area of the Chenyouranxi River valley, and Donpu station is another one located in the middle the area. Total of 25 years rainfall and discharge dated from 1980 to 2005 were used in this study. Two methods were considered to choose data for statistic analysis. In the first method, over $100 \mathrm{~mm}$ accumulated rainfall data would be seen as a rainfall event, with each rainfall event and its discharge were compared together and the maximum data was chosen. The second method is to choose the maximum discharge from each of a half year. Because of the lack of discharge data in Donpu survey station, only data were chosen from 1990 to 2005.

The goodness of fit statistic check was made by the SLSC value to decide which distribution to be used. On the other hand, an area ratio was used in this study to calculate discharges of each torrent,
Table 2 Landslide intensity, grouped to four classes ${ }^{10)}$

\begin{tabular}{c|c|c|c}
\hline \multirow{2}{*}{$\begin{array}{c}\text { Estimated } \\
\text { volume in } \\
\text { each grid }\left(\mathrm{m}^{3}\right)\end{array}$} & \multicolumn{3}{|c}{ Expected landslide velocity } \\
\cline { 2 - 4 } & $\begin{array}{c}\text { Fast } \\
\text { moving }\end{array}$ & $\begin{array}{c}\text { Rapid } \\
\text { moving }\end{array}$ & $\begin{array}{c}\text { Slow } \\
\text { moving }\end{array}$ \\
\hline$<50$ & Slight & Slight & Slight \\
\hline $50-100$ & Medium & Slight & Slight \\
\hline $100-150$ & High & Medium & Medium \\
\hline $150-300$ & High & High & Medium \\
\hline $300-600$ & Very high & High & High \\
\hline$>600$ & Very high & Very high & Very high \\
\hline
\end{tabular}

because of main flow discharge could be seen as the conflux of total tributaries and torrents. Additionally, there is always high sediment concentration discharge in heavy rainfall time. The source of sediment from each torrent and tributary is the sub basin of every torrent. Although in the procedure sediment movement from tributaries and torrents to the main flow the effect of sediment delivers ratio should be considered, in this study, this factor was ignored. Finally, we defined that area ratio is the diversion of sub-basin area of torrent and total watershed area of main flow.

Step3: The torrents were simulated to get the deposited area by Flo-2D software. In each torrent, we assumed a sediment concentration of 0.4 , continued for 35 minutes debris flow event. The input data includes the topographic data made in step 1 and the discharge data calculated in step 2. After simulating, we could get two grid-cell files, which are flow depth and velocity. From flow depth, multiplying with the area of grid-cell, the deposited volume could be easily calculated.

Step4: The main propose is to make the division of deposit area. A concept of landslide intensity was considered as a measure to divide levels ${ }^{11)}$. According to previous study ${ }^{12)}$, landslide intensity $(I)$ is a function of landslide volume $(v)$ and of landslide velocity (s), as Eq.(4)

$$
I=f(v, s)
$$

In this formula, landslide intensity means the destructiveness of landslide; the more the value is, it shows that the landslide is destructive. From Table 1, several classes were decided by comparing velocity of debris flow in each grid-cell. Debris flow velocity scales were established according to human response, velocity over $10 \mathrm{~m} / \mathrm{s}$ means that human could not evacuate from the place; the normal running velocity of human is $6.67 \mathrm{~m} / \mathrm{s}$; the average speed that adults walk is about $1.56 \mathrm{~m} / \mathrm{s}$, and the slowest walking speed in the world is about $0.61 \mathrm{~m} / \mathrm{s}$. Velocity during these values become 
Table 4 Discharge of two observed station

\begin{tabular}{c|c|c|c|c|c|c|c|c|c}
\hline \multicolumn{2}{c|}{ Discharge per period year } & 200 & 100 & 80 & 50 & 30 & 20 & 10 & 5 \\
\hline $\begin{array}{c}\text { Discharge } \\
\left(\mathrm{m}^{3} / \mathrm{s}\right)\end{array}$ & Ronshinchou & 16930 & 11634 & 10303 & 7962 & 5992 & 4759 & 3156 & 2013 \\
\cline { 2 - 10 } & Donpu & 2810 & 2116 & 1929 & 1583 & 1269 & 1058 & 761 & 523 \\
\hline
\end{tabular}

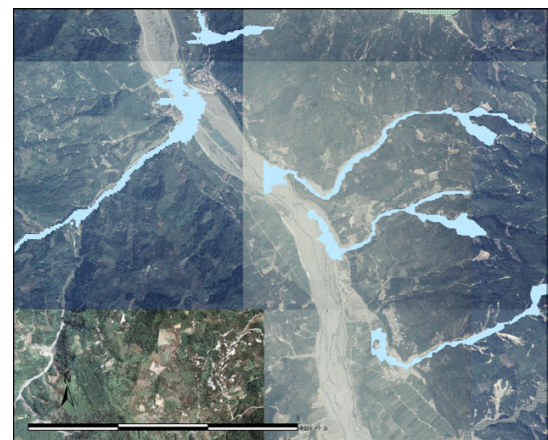

Fig.2 The accumulated type of debris flow Type 1

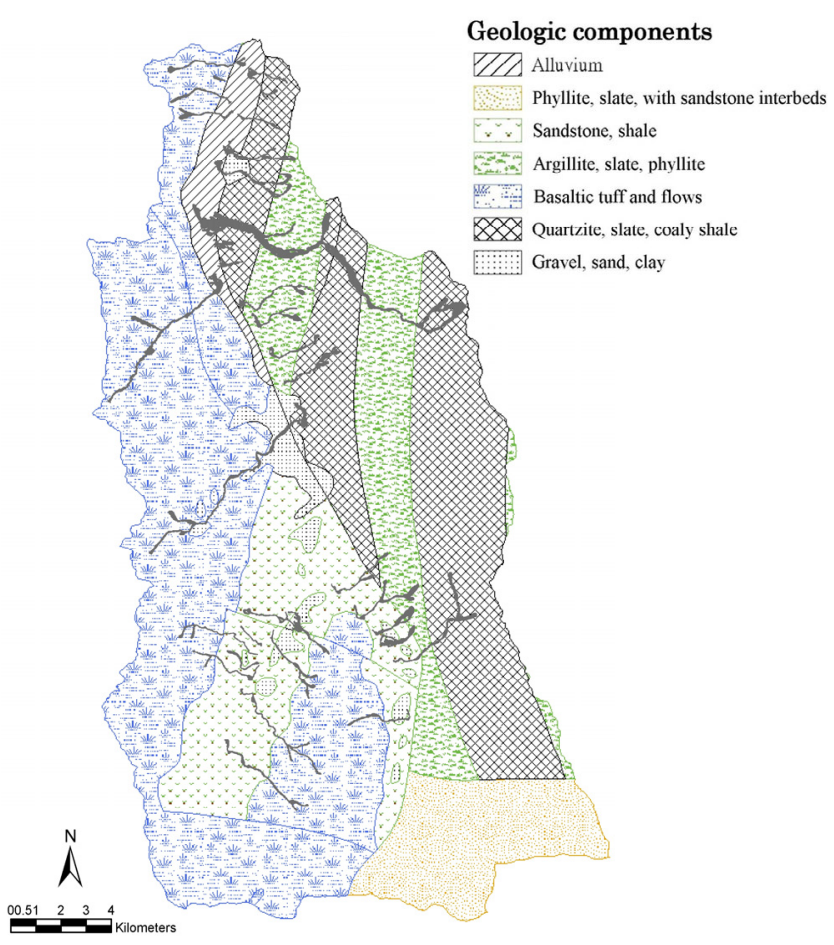

Fig.5 Geologic components of the watershed

several classes, and these classes were used to make several levels: fast moving, medium moving and slow moving. Fast moving included velocity classes 6 and 5; rapid moving included velocity class 4; slow moving included velocity classes 1, 2 and 3, and comparing with sediment volume, four landslide intensity levels, very high, high, medium and slight could be established(Fig.2).

\section{RESULT AND DISCUSSION}

\section{(1) Hydrologic frequency analysis result}

We used the observed data to calculate the relationship of discharge and return period time. From the statistical results of discharge ${ }^{13)}$, we found 9 kinds of extreme-value distributions to compare

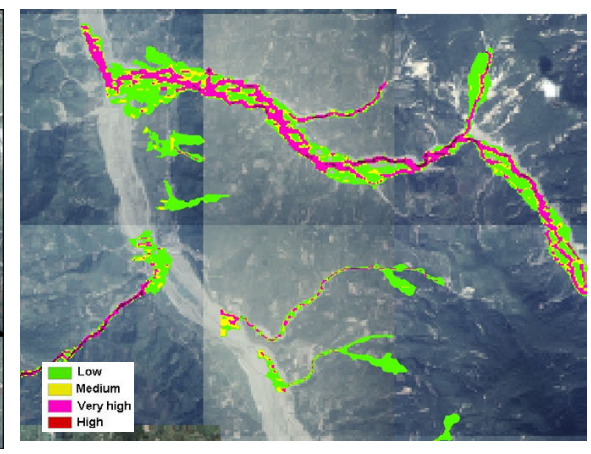

Fig.4 The hazard level of the Chenyoulanxi watershed

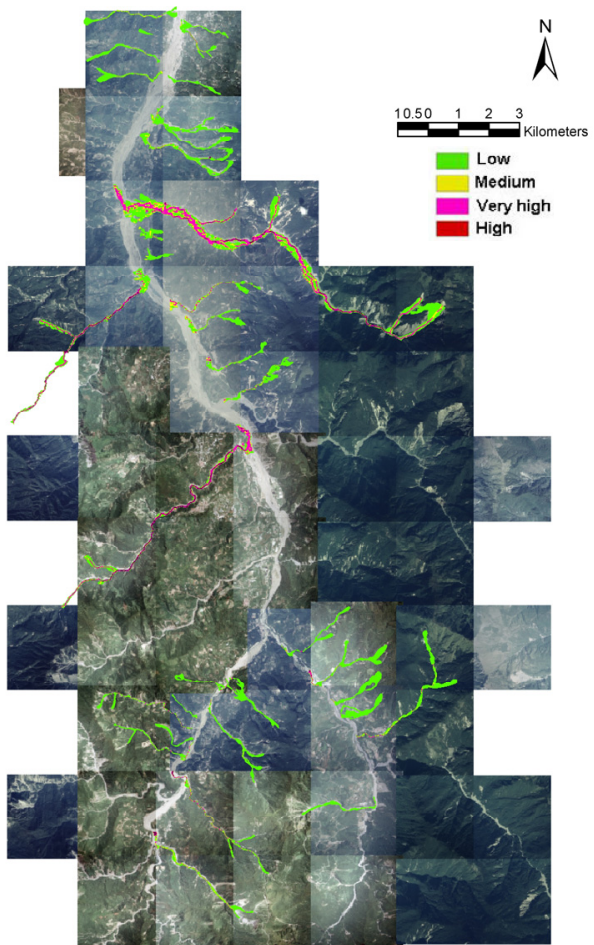

Fig.6 The hazard map of the Chenyoulanxi watershed

which is the best. The SLSC values of each distribution were used to check the pros and cons of each distribution. From Table 3, the range of Ronshinchou station is from 0.04 to 0.116 , and the range of Donpu station is from 0.02 to 0.155 . According to the previous study by Takara ${ }^{14)}$, the best range for SLSC value is less than 0.02 but it is also available that if SLSC is between 0.02 and 0.04 . Therefore, comparing with every value, finally we chose the result of Generalized Pareto Distribution (Gp) to estimate the discharge extreme-value.

Table 4 described the discharge results of two survey stations. To calculate this result, the bootstrap method was used to calculate discharges 
extreme-value of several return periods from 5 years to 200 years for 2000 times. Because of maximum discharge surveyed from the two stations are $4650 \mathrm{cms}$ (Ronshinchou) and $1860 \mathrm{cms}$ (Donpu), respectively, the discharges of 20-year (Ronshinchou) and 80-year (Donpu) return periods were chosen.

\section{(2) Flow simulation result}

The simulation results from the Flo-2D software model, the flow route, and deposited area we got approximately match with the alluvial fans shown in aerial photographs. However, because of restricted conditions of the Flo-2D, even if it could be clearly shown that how debris flows flow down the streams and how wide the alluvial fans would be developed, the sediment activities and where the debris flow is induced are difficult to draw.

From accumulated types of debris flows, some characteristics were shown. In our study, we categorized them as Type1 and Type2 (Fig.2, Fig.3).

It is well-known that sediment movement is influenced by rainfall intensity accumulated precipitation and gradient of hill slope. After slicing down the hill slope, sediment with water became alluvial fans on the downstream. However, in this study, we found that sediment was not only submerged in the downstream but also accumulated in the procedure of movement. In Type1, some of sediment brought to downstream, and an alluvial fan was developed in the border between main flow and the torrent. Moreover, some of sediment could be found in the upper or middle streams. Therefore, numerous sediment distributed in fans would directly damage the villages, the part of which entered in the main flow would also affect the discharge of the main flow. The sediment distributed in the hillslopes may become the materials to cause the next disaster. In Type2, not much sediment accumulate in both alluvial fan and hillslope, the accumulated range is almost limited in the flow route. It means that there is not much sediment be eroded and brought to the downstream or the torrent bank could not be easily eroded. Consequently, it could be presumed that in Type2, debris flow events would bring less effect to villages and the main flow.

Geologic conditions are differently distributed in the left and right parts of the Chenyouranxi watershed as shown in Figure 4 and Figure 5. The components and soil erosion on the left and right banks of the main flow are also not the same. From the simulation result, it is apparent that distribution of accumulated types could also be divided to right and left parts according to the fault. Thus, it could be assumed that reasons to cause different types on the right and left parts depend on the degree of soil erosion and gradient of the slope.

In the right part, the type of deposited areas belong to Type1, which sediments are accumulated in the hillslopes, alluvial fans, and main flow. The geologic components of this part are shale, quartziferous sand, and metamorphic rock, which are easily eroded. Furthermore, a road passed by and people are crowd in alluvial fans of these areas, which results in rapid weathering and erosion of rock. From these reasons with simulation results, it could be explained that why the most serious and frequency disasters were always happened in the right part which cost serious lost on human life and property in past years.

In the left part, especially the west-south part of the watershed, the debris flow run out type is quite different. In this part, sediment accumulated range is not very wide, but when comparing accumulated volume with Type1, the volume is approximate in the same range. As a result, it means that when concerning the sediment movement of this part, effect of sediment deliver ratio should be considered because of numerous sediment accumulated in the flow route.

\section{(3) Hazard mapping}

Figure 6 shows a hazard map of the Chenyouranxi valley, with four levels divided by colors: green is slight, yellow is medium, pink is high and deep red is very high (Table 2). Most of the area belongs to slight level, which is about $10.45 \mathrm{~km}^{2}$; high level is second, the area is about $1.61 \mathrm{~km}^{2}$; the area of medium level is about $1.35 \mathrm{~km}^{2}$; the area of very high level is about $0.47 \mathrm{~km}^{2}$. Most of level high and very high were distributed in the middle of torrent flow route and the main flow.

From this map, the result shows that if there is a 80-year and 20-year return period rainfall events happened in the north and meddle parts, it may cause debris flow. However, in this rainfall event, deposited depth in most of places would be less than 0.5 meters, and velocity in most of places is between 1.56 to $6.67 \mathrm{~m} / \mathrm{s}$. This shows that when ignoring the other environmental conditions, the depth and velocity would not be a threaten to human, although there are sediment accumulated in torrents or in places where human live. People living there could be safely evacuated to shelters.

Debris flow dangerous levels could be distinguished by this method. There are some significant factors used to judge the dangerous level, such as (1) the recurrence of debris flow, (2) the vegetation of the area, and (3) if there is drift 
wood in debris flow or not. Furthermore, if there are enough water and sediment materials, the disaster would happen again. Therefore, although in this simulation, most of areas belong to slight level, it does not mean that there will not have any disaster in the next rainfall event.

\section{CONCLUSION}

The mathematics modeling of debris flows in the Chenyouranxi valley based on aerial photographs and digital terrain model data was used to establish a hazard mapping method. The main conclusion could be drawn as follows:

(1) Rainfall and discharge data from Ronshinchou and Donpu survey stations were used in the study. The discharge extreme values could be calculated and checked by SLSC value. In the north part of the watershed (Ronshinchou), the calculating discharge extreme value is $4650 \mathrm{~m}^{3} / \mathrm{s}$, which is 20-year return period, and in the south part (Donpu), the discharge extreme value is $1860 \mathrm{~m}^{3} / \mathrm{s}$, which is 80 -year return period. The discharge of each torrent could be calculated by the discharge of the main flow and the ratio of the areas. The accumulated volume quantity of each torrent from simulation did not show positive relationship with the discharge of each torrent.

(2) The simulation results from Flo-2D could be a good material to interpret the probable accumulated range made by debris flows. According to the categorized method, the range of dangerous level for torrents could be decided as demand. In the study, the deposited type was divided into two forms which are related to the sediment accumulated type, geology, and topographic reasons of alluvial fans in the downstream of the torrent.

(3) The simulation results of debris flow in the Chenyourenxi valley could be matched with the real situation in aerial photograph. However, as we used this method to recognize torrents with potential danger or not, there still many situations are difficult to judge, which should be evaluated by the other method, such as using statistic method to calculate the probability of landslide.

(4) Hazard map could be drawn according to flow velocity and sediment deposited volume, which means the landslide intensity of each element. In this watershed, the total deposited area is $13.89 \mathrm{~km}^{2}$, the very high level of landslide intensity is about $0.47 \mathrm{~km}^{2}$, the high level is about $1.61 \mathrm{~km}^{2}$. The most of the areas belong to slight level, the area is about $10.45 \mathrm{~km}^{2}$.

Actually, debris flow is simply a part of landslide phenomena, in particular when heavy rainfall comes, sediment disasters including all kinds of types of sediment movement would happen. The best complete assessment is to include most of the sediment movement phenomena in total area, not only to the torrents and divide to different dangerous levels.

For these reasons, in the future study, we wish to expand the study from debris flow to include total landslide phenomena mapping program, especially including landslide, mudflow and debris flow in the whole Chenyourenxi valley watershed.

\section{REFERENCES}

1) Okimura, T.: Estimate probability of landslide and assessment danger level- New development on assessing danger level of wasting on surface layer causing by heavy rainfall, DPRI, pp. 59-67, 2003. (in Japanese)

2) Chen, Z. and Wang, J.: Landslide hazard mapping using logistic regression model in Mackenzie Valley, Canada, Natural hazard, Vol.42, pp.75-89, 2007.

3) Evans, S.G., Guthrie, R.H., Roberts, N.J. and Bishop, N.F.: The disastrous 17 February 2006 rockslide-debris avalanche on Leyte Island, Philippines: a catastrophic landslide in tropical mountain terrain, Natural Hazards Earth System Sciences, Vol.7, pp.89-101, 2006.

4) Chen, Y.J.: Using spatial information technology to quantify the volume of debris flow in the watershed of Chenyoulen stream, master thesis, pp.13-14, 2004.

5) Lin M. L.: Some effects of geological factor on the behavior of debris flow in Taiwan, Debris flow geologic investigation and hazards mitigation conference, pp.6-1-6-28. (in Chinese)

6) Soil and Water Conservation Bureau (SWCB): http://www.swcb.gov.tw (in Chinaese)

7) O'Brien J. S.: Flo-2D users manual: http://www.flo-2d.com, 2006.

8) Mikoš M., Fazarinc, R., Majes, B., Rajar, R., Žagar, D., Krzyk, M., Hojnik, T. and Četina, M.: Numerical simulation of debris flows triggered from the Strug rock fall source area, W Slovenia, Natural Hazards Earth System Sciences., Vol.6, pp.261-270, 2006.

9) Bertolo, P. and Wieczorek, G. F.: Calibration of numerical models for small debris flows in Yosemite Valley, California, USA, Natural Hazards Earth System Sciences., Vol.5: 993-1001, 2005.

10) Cardinali, M., Reichenbach, P., Guzzetti, F., Ardizzone, F., Antonini, G., Galli, M., Cacciano, M., Castellani, M. and Salvati, P.: A geomorphological approach to the estimation of landslide hazards and risks in Umbria, Central Italy, Natural hazard and Earth System Sciences, Vol.2, pp.57-72, 1996.

11) Jakob, M. and Oldrich, H.: Debris flow hazards and related phenomena, Springer, 2005.

12) Cardinali, M., Galli, M., Guzzetti, F., Ardizzone, F., Peichenbach, P. and Bartoccini, P.: Rainfall induced landslides in December 2004 in south-western Umbria, central Italy: types, extent, damage and risk assessment, Natural Hazards Earth System Sciences, Vol.6, pp.237-260, 2006.

13) Japan institute of construction engineering (JICE): http://www.jice.or.jp (in Japanese)

14) Takara, K.: Recent advancement and perspective of hydrologic frequency analysis, J. Japan Soc. Hydrol. \& Water Resour., Vol.11-7, 1998. (in Japanese)

(Receive September 30, 2007) 